\title{
PRICES VS. QUANTITIES IN A SECOND-BEST SETTING
}

\author{
Philippe QUIRION, CIRED (CNRS-EHESS) \\ 45 bis avenue de la Belle Gabrielle, F-94736 Nogent-sur-Marne cedex, France \\ Tel. +33 (0) 1439473 95, Fax +33 (0) 1439473 70, quirion@ centre-cired.fr
}

\section{Abstract}

The choice between taxes and tradable permits has been independently analysed by two distinct research traditions. The first proceeds from Weitzman's partial equilibrium stochastic model and concludes that a tax should be preferred if the marginal abatement cost curve is steeper than the marginal environmental benefit curve. The second utilises deterministic general equilibrium models with pre-existing distortionary taxes. It concludes that non-revenue-raising instruments (e.g., grandfathered tradable permits) are costlier than revenue-raising ones (e.g., a tax on every unit of pollution or auctioned permits).

To build a bridge between these two traditions, we introduce in Weitzman's model a positive cost of public funds due to pre-existing distortionary taxes. The tax admits a greater comparative advantage over the permits, as compared to Weitzman's classical result. Then, we assume that the regulated industry blocks any proposal that poses it too high an expected burden. This may require a transfer to firms, in the form of freely-allocated permits or lump-sum tax rebate. It turns out that if this acceptability constraint is binding, then the comparative advantage of taxes over permits is still reinforced. Quantitatively, even if the marginal benefit function is $50 \%$ more steeply sloped than the marginal cost function, the price instrument should be preferred.

We also compare the expected net benefit of these two instruments to a contingent instrument which leads to the ex post optimum. The superiority of the contingent instrument over the quantity one is higher than in first-best.

Keywords: Environmental taxes, policy choice, tradable permits, second best, uncertainty

JEL codes: D81; Q25; Q28 


\section{Introduction ${ }^{1}$}

The formal economic analysis of the choice between taxes and tradable permits for protecting the environment dates back to Weitzman (1974)'s seminal paper. In a partial equilibrium framework, Weitzman showed that, as long as the abatement cost curve is known with certainty, both instruments are equivalent. However, in case of uncertainty on abatement costs, a tax should be preferred if and only if the marginal abatement cost curve is steeper than the marginal environmental benefit curve. His model has been elaborated in a variety of ways and applied to various empirical questions, e.g. climate change (Pizer, 1999).

Recently, within the "double-dividend" debate, a bulk of papers examined the pros and cons of various instruments - including taxes and tradable permits - in a general equilibrium framework taking into account pre-existing distortionary taxes ${ }^{2}$. However, because they utilise deterministic models, these papers do not take into account Weitzman's results ; taxes and permits differ only in that permits are freely (and exogenously) distributed whereas taxes revenues are used to reduce existing, distortionary, taxes. In other words, "permits" are modelled as a tax whose revenue are transferred lump-sum to regulated firms instead of being used for cutting other taxes. By the very definition of a distortionary tax, in these models, "taxes" thus always perform better than "permits". In such a setting, auctioned rather than freely distributed permits are perfectly equivalent to taxes.

This view of taxes as being intrinsically revenue-raising, as opposed to permits being either auctioned or freely allocated, is widespread. It explains why numerous authors, such as Baumol

\footnotetext{
${ }^{1}$ I thank two anonymous referees, participants at EAERE and PIREE 2001 conferences, Khalil Helioui and JeanCharles Hourcade for useful comments, as well as Institut français de l'énergie for financial support. The usual disclaimer applies.

${ }^{2}$ Cf. Fullerton and Metcalf (2000) and Parry (1997) for analytical models, Goulder et al. (1999a, 1999b) and Parry et al. (1999) for analytical and numerical models applied to sulphur dioxide, nitrogen dioxide and carbon dioxide abatement, respectively.
} 
and Oates $(1988)^{3}$ or Jensen and Rasmussen $(2000)^{4}$, stated that freely allocated permits trigger less opposition from regulated industries than taxes. Indeed the latter would increase their private costs. This issue is of the utmost importance since representatives of regulated industries carry significant weight in the political process. Environmental policies that pose serious burden on these industries may stand little chance of political survival. As a consequence, permits are freely allocated in almost every existing and projected schemes (Boemare and Quirion, 2002). Admittedly, non-revenue-raising instruments let more people worse off than revenue-raising ones since they are socially less efficient. However, the latter typically poses a relatively high burden on a small number of firms whereas the social cost of the former is higher but more evenly spread among firms and households. Firms affected by revenue-raising instruments are thus more likely to incur the costs of political mobilisation. This is confirmed by various empirical studies, e.g. Lévêque $e d$. (1996), and by "political market" models of instrument choice, e.g., Kehoane et al. (1998). Dealing with the opposition to revenue-raising instruments from regulated industry is thus of the utmost importance.

However, such a characterisation of taxes and permits neglects the possibility, put forward in particular by Mumy (1980) and Pezzey (1992) of a "charge-subsidy" scheme under which each polluting firm pays a charge

$p\left(Z-Z_{B}\right)$

to the pollution control authority, where $p$ is the charge or subsidy rate, $Z$ the effluent level and $Z_{B}$ is the baseline effluent right which is initially given to each existing firm by the authority. As indicated by figure 1 , if a firm's effluent is less than its baseline $\left(Z<Z_{B}\right)$, it receives a subsidy from the authority. Defining such baseline is not more difficult for the authority than choosing

\footnotetext{
3 "Although a system of effluent charges will reduce total abatement costs, it will impose a new financial burden, the tax bill itself, on polluting firms. [...] However, there is an alternative that gets around the problem: A permit system can be initiated through a free initial distribution of the permits among current polluters." (pp. 178-9).
} 
an amount of freely allocated permits. In practice, both are generally based on past emissions the so-called grandfathering - or on an emission/output ratio applied to past or present production - labelled, by respect, benchmarking and output-based allocation ${ }^{5}$.

\section{Figure 1. The tax-subsidy scheme}

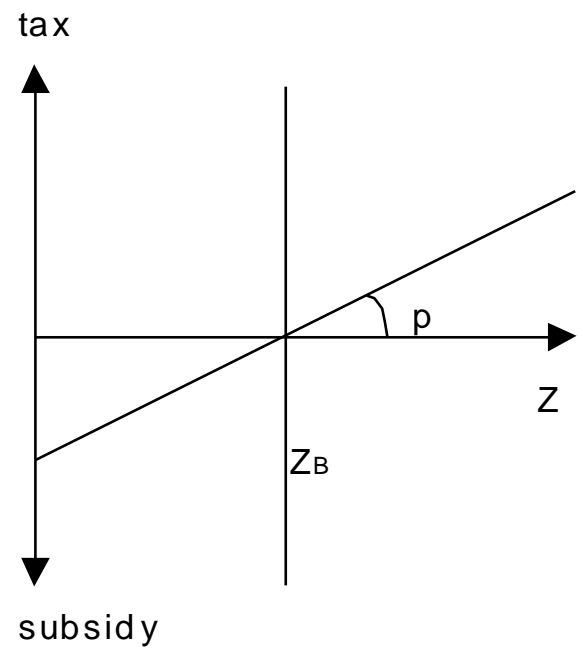

Pezzey infers that the choice between taxes and permits should be based, not on distributional impacts, but on efficiency concerns. In particular it should be based on how well each instrument copes with uncertainty, along the line put forward by Weitzman.

Schöb (1996) first analyses the choice between price and quantity instruments in a world with distortionary taxation and concludes that results of Weitzman remain valid. However he utilises a modified form of partial equilibrium models by Nichols (1984) and Lee and Misiolek (1986) which contradicts recent research on the double dividend. In a brief appendix, we compare his model with ours and justify our modelling choice.

\footnotetext{
4 "A tradable permits system may in practice be preferred to a uniform tax on $\mathrm{CO}_{2}$, precisely because it entails an opportunity to address [concerns such as worker displacement and stranded costs] by means of permits disbursements" (pp. 111-2).

5 A common characteristic of existing environmental charges is the inclusion of exemptions and tax reliefs, in particular for manufacturing industry (Ekins and Speck, 1999). However, those exemptions are generally less efficient than the charge-subsidy scheme presented here, in particular because they often charge a lower tax rate on some firms.
} 
At last, Bovenberg and Goulder (2001, p. 48) state, without demonstrating but referring to the above-mentioned paper by Schöb, that "Second-best considerations have no bearing on the choice, under uncertainty, between emissions taxes and auctioned quotas, since auctioned quotas and emissions taxes are equivalent in terms of their tax-interaction and revenue-recycling effects." However, under uncertainty, we will see that auctioned quotas and emissions taxes differ in terms of their expected cost, thus also in terms of their expected tax-interaction effect.

The present paper shows that the choice between a price and a quantity instrument is not independent from pre-existing distortions. More precisely, if the cost of the regulation is strengthened by pre-existing distortions, the relative advantage of taxes over permits is greater than in first-best. Since most theoretical works (especially those cited above) concludes that preexisting distortions raise the cost of regulation, we argue that those distortions reinforce the rationale for taxes over permits.

Furthermore, we show that not only Pezzey is right to claim that free permits do not deal with adverse impacts on regulated industry better than a charge-subsidy scheme, but that the opposite is true. If the authority determines the baseline of the charge-subsidy scheme and the amount of permits freely allocated in order to cap the cost for regulated industry, the relative advantage of taxes over permits is still higher than in the previous case.

We also compare the expected net benefit of these two instruments to a "contingent" instrument which leads to the ex post optimum. It turns out that the superiority of the contingent instrument over the quantity instrument is higher than in first-best. No general result may be derived concerning the influence of pre-existing distortions on the superiority of the contingent instrument over the price instrument.

The rest of the paper is organised as follows. After presenting the model (section 2), we analyse three variants in turn. We first consider that the authority can overstep industry pressure and thus uses revenue-raising instruments (section 3). We then study non-revenue-raising 
instruments, i.e., a freely allocated permits system and a charge-subsidy scheme such that the expected value of subsidies equals that of charges (section 4). Finally, we consider that the regulated industry kills any proposal that poses it an expected burden higher than an exogenous level (section 5). The amount transferred as free permits or baseline effluent right of the chargesubsidy scheme is now chosen by the authority. Last, we provide several arguments indicating that for cutting $\mathrm{CO}_{2}$ emissions, a charge-subsidy scheme could be better accepted than a tradable permit system, both by industry and environmental groups (section 6).

\section{The model}

\subsection{Abatement costs and benefits}

Following Weitzman (1974), we use quadratic approximations to measure abatement costs. Primary (private) ${ }^{6}$ abatement cost $C$ is perfectly known by the firm, but includes, for the authority, a stochastic element $\theta$, standardised such that $E[\theta]=0$ :

$C(q, \theta) \approx c_{0}+\left(c_{1}+\theta\right) q+\frac{c_{2}}{2} q^{2}$

where $q$ is the abatement in pollution and $c_{i}>0 \quad \forall i \in\{0,1,2\}$. From (2),

$C_{q}(q, \theta) \approx c_{1}+\theta+c_{2} \cdot q$

The environmental benefit function is also taken from Weitzman (1974) except that it is known with certainty ${ }^{7}$ :

$B(q)=b_{0}+b_{1} \cdot q-\frac{b_{2}}{2} q^{2}$

where $b_{i}>0 \quad \forall i \in\{0,1,2\}$. From (4):

\footnotetext{
${ }^{6}$ Throughout the paper, we assume that regulated firms are unable to pass the abatement cost on to consumers.
} 


\subsection{Regulator's objective}

In Weitzman's first best framework, the authority maximises expected welfare $E[B(q)-C(q, \theta)]$. As shown by Sandmo (1975) and the recent literature on the "doubledividend", this formula is valid only when lump-sum taxes are available. Otherwise, compared to the primary abatement cost, the general equilibrium abatement cost is:

- increased by the interaction between pre-existing distortionary taxes and the new environmental tax (the "tax-interaction effect")

- reduced if the revenues raised by the environmental tax or auctioned permits are used to cut distortionary taxes (the "revenue-recycling effect").

If the latter outweigh the former, the general equilibrium cost of an environmental tax or auctioned permit scheme is lower than the private abatement cost. Then a "double-dividend" as defined by Parry (1995) is said to occur ${ }^{9}$. This case may hold under certain circumstances, especially:

- if labour taxes are too high, from a "Ramsey" taxation perspective, and if a significant part of the environmental tax is paid for by non-wage earners ${ }^{10}$;

- in case of nominal rigidities in the labour market;

- if environment quality is a relatively weak substitute for leisure;

- if the decrease in fossil fuel imports lessens producers' rents;

\footnotetext{
${ }^{7}$ Benefit uncertainty matters only if correlated with cost uncertainty (Stavins, 1996).

${ }^{8}$ Intuitively, because of the distortionary nature of the tax, every public good becomes more expensive, including the environment.

${ }^{9}$ If, in addition, the net abatement cost (neglecting the environmental benefit) is negative, there is a "strong doubledividend" according to Goulder (1995)'s terminology.
} 
- if the pro-cyclical nature of energy taxes, compared to labour taxes, is taken into account (Helioui, 1997).

If and only if lump-sum taxes are not available, non-revenue-raising instruments (free permits or a charge-subsidy scheme in which the expected total subsidy equals the expected total tax) are always costlier than revenue-raising ones. Indeed, the former do not provide the revenuerecycling effect, nevertheless their cost is raised by the tax-interaction effect. It should be stressed that this superiority of revenue-raising instruments over other policies - the "weak double-dividend", to follow again Goulder (1995)'s terminology - is uncontroversial.

With linear demand, supply and marginal cost curves, all goods being equal substitutes for leisure, labour being the only production factor and a tax on labour being the only pre-existing tax, Goulder et al. (1999b, p. 341) showed that no strong double-dividend occurs and that the ratio of the general equilibrium cost of a tax relative to its primary cost equals the marginal cost of raising public funds through the pre-existing tax, $\mu \geq 1$. We use this result throughout the present paper. Graphically, as shown by Parry (1995, fig. 2, lower panel) the marginal general equilibrium cost curve of reducing pollution is steeper than without pre-existing distortionary taxation.

On top of this general equilibrium cost of revenue-raising instruments $\mu . C(q, \theta)$, a free permit or a charge-subsidy scheme entails the cost of the transfer $(\mu-1) p \cdot Z_{B}$ where $Z_{B}$ is the amount of free permits, or the baseline effluent right as in equation (1). This modelling approach was used by all macroeconomic deterministic models referred to in footnote 2 .

Hence expected welfare, which is the regulator's objective, now is:

$$
E\left[B(q)-\mu . C(q, \theta)-(\mu-1) p . Z_{B}\right]
$$

\footnotetext{
${ }^{10}$ This explains why most general equilibrium analysis applied to European countries exhibit a strong double dividend (Intergovernmental Panel on Climate Change, 2001).
} 
where $\mu-1$ is the marginal excess burden. In this expected welfare function, as in Weitzman's original one, the revenue from taxes or auctioned permits is not directly included, since this wealth is only transferred from firms to the State. Admittedly, this revenue allows the State to reduce pre-existing taxes (revenue-recycling effect), but this is outweighed by the taxinteraction effect. Furthermore, as shown by the papers referred to in footnote 2, distributing grandfathered allowances (or their equivalent as a price instrument, i.e., baseline effluent right) leaves the tax-interaction effect unchanged while reducing the revenue raised, hence the revenue-recycling effect. This appears in the last part of our objective function.

\section{Optimal instruments when the authority can overstep industry pressure}

\subsection{Optimal auctioned permits}

The authority obviously sets $Z_{B}=0$ and thus chooses $q$ that maximises $E[B(q)-\mu . C(q, \theta)]$.

The solution $\hat{q}_{R R}$ (for revenue-raising) proceeds from the first-order condition:

$E\left[B^{\prime}(\hat{q})\right]=\mu \cdot E\left[C_{q}^{\prime}(\hat{q}, \theta)\right]$

hence $\hat{q}_{R R}=\frac{b_{1}-\mu \cdot c_{1}}{\mu \cdot c_{2}+b_{2}}$

The price of the permits equals marginal abatement cost:

$p\left(\hat{q}_{R R}, \theta\right)=c_{1}+\theta+c_{2} \frac{b_{1}-\mu \cdot c_{1}}{\mu \cdot c_{2}+b_{2}}$

If and only if $\mu=1$, we are back to Weitzman's result. When the marginal cost of public funds is strictly greater than 1 , the optimal quantity and resulting permits price are lower than in firstbest: $\hat{q}_{R R}<\hat{q}_{F B}$ and $p\left(\hat{q}_{R R}, \theta\right)<p\left(\hat{q}_{F B}, \theta\right)$, where subscripts $F B$ denote Weitzman's first-best results. Intuitively, taking into account general equilibrium costs, the authority sets a lower abatement target. 


\subsection{Optimal tax on every unit of pollution}

The firm chooses the abatement amount $h(p, \theta)$ knowing the state of nature $\theta$, by equalising the marginal abatement cost (3) to the tax $p$ :

$C_{q}(h(p, \theta), \theta)=p$

The authority chooses the tax rate $\tilde{p}_{R R}$ that maximises the expected surplus given this response function $h(p, \theta)$ :

$\tilde{p}=\arg \max _{p} E[B(h(p, \theta))-\mu \cdot C(h(p, \theta), \theta)]$

The first-order condition is:

$E\left[B^{\prime}(h(\tilde{p}, \theta)) h_{p}(\tilde{p}, \theta)\right]=\mu \cdot E\left[C_{q}(h(\tilde{p}, \theta), \theta) h_{p}(\tilde{p}, \theta)\right]$

which, combined to (6), implies:

$\tilde{p}=\frac{E\left[B^{\prime}(h(\tilde{p}, \theta)) h_{p}(\tilde{p}, \theta)\right]}{\mu \cdot E\left[h_{p}(\tilde{p}, \theta)\right]}$

At this optimal price ex ante corresponds the profit-maximising abatement: $h(\tilde{p}, \theta)$.

By the expression of marginal abatement cost (3) and (6):

$h(\tilde{p}, \theta)=\frac{\tilde{p}-c_{1}-\theta}{c_{2}}$

hence: $h_{p}(\tilde{p}, \theta)=\frac{1}{c_{2}}$

Inserting these two equations into (7):

$\tilde{p}_{R R}=\frac{b_{1} \cdot c_{2}+b_{2} \cdot c_{1}}{\mu \cdot c_{2}+b_{2}}$ 
hence: $h\left(\tilde{p}_{R R}, \theta\right)=\frac{b_{1} \cdot c_{2}+b_{2} \cdot c_{1}}{\left(\mu \cdot c_{2}+b_{2}\right) c_{2}}-\frac{c_{1}+\theta}{c_{2}}$.

\subsection{Comparison of price and quantity instruments without transfer}

As in the first-best model, both instruments yield the same optimal expected level of abatement and the same optimal expected price/tax:

$$
\begin{aligned}
& E\left[h\left(\tilde{p}_{R R}, \theta\right)-\hat{q}_{R R}\right]=0 \\
& E\left[\tilde{p}_{R R}-p\left(\hat{q}_{R R}, \theta\right)\right]=0
\end{aligned}
$$

The difference between both instruments, in terms of expected environmental benefit and primary cost, is the same as in first best:

$$
E\left[B\left(h\left(\tilde{p}_{R R}, \theta\right)\right)-B\left(\hat{q}_{R R}\right)\right]=-\frac{b_{2} \sigma^{2}}{2 c_{2}{ }^{2}} \leq 0
$$

where $\sigma^{2}=\operatorname{var}(\theta)$.

$$
E\left[C\left(h\left(\tilde{p}_{R R}, \theta\right), \theta\right)-C\left(\hat{q}_{R R}, \theta\right)\right]=-\frac{\sigma^{2}}{2 c_{2}} \leq 0
$$

The ex ante optimal tax leads, compared to permits issued in the ex ante optimal quantity, to a lower expected environmental benefit and a lower expected abatement cost. These results, valid both in first- and second-best are not laid out in Weitzman's article, but they stem directly from the author's model.

The social surplus of the ex ante optimal tax, as compared to the ex ante optimal permit scheme, is:

$$
\Delta_{R R} \equiv E\left[B\left(h\left(\tilde{p}_{R R}, \theta\right)\right)-\mu \cdot C\left(h\left(\tilde{p}_{R R}, \theta\right), \theta\right)\right]-E\left[B\left(\hat{q}_{R R}\right)-\mu \cdot C\left(\hat{q}_{R R}, \theta\right)\right]=\frac{\sigma^{2}\left(\mu \cdot c_{2}-b_{2}\right)}{2 c_{2}{ }^{2}}
$$


If and only if $\mu=1$, we are back to Weitzman's result. When the marginal cost of public funds is strictly greater than 1 , the tax admits a greater comparative advantage over the permits, as compared to Weitzman's result: $\Delta_{R R}>\Delta_{F B}$.

\subsection{Why is the expected abatement cost higher for optimal permits than for optimal taxes?}

The superiority of taxes over permits concerning the expected abatement cost, being of the utmost importance for our subsequent results, deserves some more comments. It stems from the convexity of the cost function and Jensen's inequality. This inequality states that, for $C(q, \theta)$ convex in $q, \quad C(E[q], E[\theta]) \leq E[C(q, \theta)]$. Combining this last equation with the above equality $E\left[h\left(\tilde{p}_{R R}, \theta\right)\right]=\hat{q}_{R R}$ and $E[\theta]=0$, we have $C\left(E\left[h\left(\tilde{p}_{R R}, \theta\right)\right], 0\right) \leq E\left[C\left(\hat{q}_{R R}, \theta\right)\right]$.

Figure 2 below provides an illustration with two values of $\theta, \underline{\theta}<0$ and $\bar{\theta}>0$ :

\section{Figure 2. Expected abatement cost for taxes and permits}

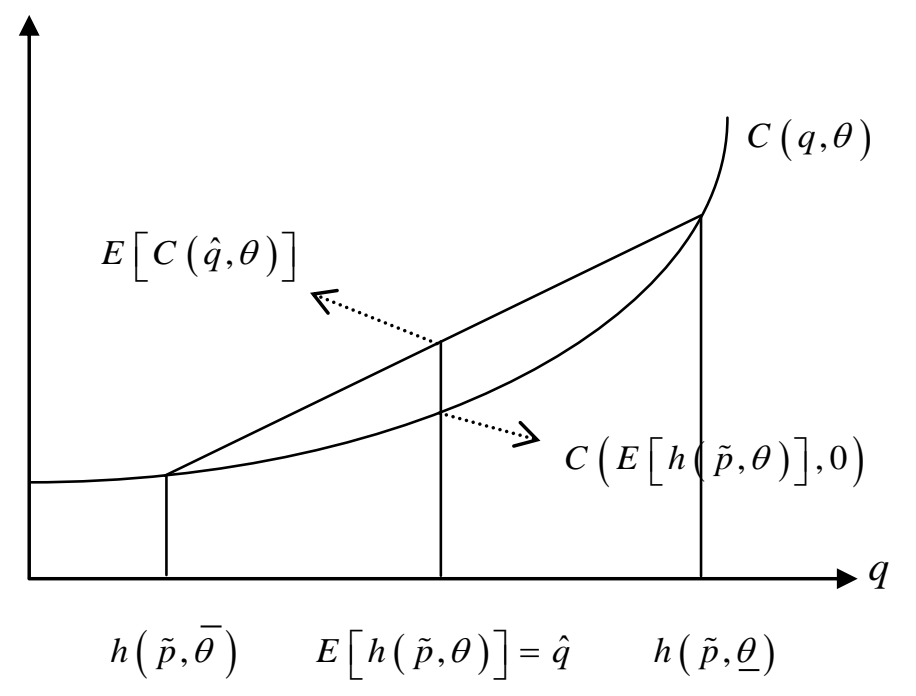

Intuitively, the tax gives firms more flexibility by letting them choose their abatement level: if the cost is higher than expected by the regulator, they will benefit from abating less and paying more tax, compared to the quantity solution. On the contrary, if the cost is lower than expected 
by the regulator, they will benefit from abating more and paying less tax. Note that with a concave benefit function this flexibility is harmful to the environment, hence a symmetrical reasoning can be made for benefits.

\subsection{Contingent revenue-raising instrument}

The instruments studied until now only exceptionally lead to the ex post optimum. The latter may be obtained if the regulator is able to use an "ideal" or "contingent" instrument, i.e., which depends on the state of nature realised, as shown by Ireland (1977). Various implementations of such a system have been proposed. In our simplified model, since there is no uncertainty on the benefits curve, several instruments may under certain assumptions be able to reach or approximate the ex post optimum: a non-linear tax; a set of various kinds of allowances, each being combined with a tax acting as a price cap and a subsidy acting as a price floor (Roberts and Spence, 1976); open market operations by the regulator to adjust the number of permits (Collinge and Oates, 1980); or a menu of call options for buying additional permits (Unold and Requate, 2001).

Nevertheless, all these implementations have potential drawbacks and involve additional complexity, as already stressed in Weitzman's original article (1974, p. 481). As a consequence, "single-value instruments", i.e., linear taxes and tradable permit schemes, are more and more

common in environmental policy ${ }^{11}$ and are still worth studying. However, it is interesting to know whether the expected advantage of the contingent instrument is worth the additional complexity.

With our cost and benefit functions, the abatement resulting from the contingent instrument is computed by maximizing ex post welfare:

$$
q_{R R}^{*}=\frac{b_{1}-\mu\left(c_{1}+\theta\right)}{\mu \cdot c_{2}+b_{2}}
$$


If $\mu=1$, we are back to Ireland (1977)'s result. Otherwise, the optimal abatement is lower. The advantage of the contingent instrument over the quantity one is:

$$
\Delta\left(C I_{R R}, Q_{R R}\right) \equiv E\left[B\left(q_{R R}^{*}\right)-\mu \cdot C\left(q_{R R}^{*}, \theta\right)\right]-E\left[B\left(\hat{q}_{R R}\right)-\mu \cdot C\left(\hat{q}_{R R}, \theta\right)\right]=\frac{\mu^{2} \sigma^{2}}{2\left(c_{2}+b_{2}\right)}
$$

This expression is (obviously) positive and (which is more interesting) increased by pre-existing distortions $(\mu>1)$. The advantage of the contingent instrument over the price instrument is:

$$
\Delta\left(C I_{R R}, P_{R R}\right) \equiv E\left[B\left(q_{R R}^{*}\right)-\mu \cdot C\left(q_{R R}^{*}, \theta\right)\right]-E\left[B\left(h\left(\tilde{p}_{R R}, \theta\right)\right)-\mu \cdot C\left(h\left(\tilde{p}_{R R}, \theta\right), \theta\right)\right]=\frac{b_{2}^{2} \sigma^{2}}{2 c_{2}^{2}\left(c_{2}+\mu \cdot b_{2}\right)}
$$

which is also positive, but reduced by pre-existing distortions.

The distortionary nature of the pre-existing tax system thus reinforces the case for a contingent instrument as compared to a quantity instrument, but weakens the case for such an instrument as an alternative to a price one.

\section{Optimal non-revenue-raising instruments}

When all permits are freely allocated or when the baseline of the charge-subsidy scheme is such that the expected value of subsidies equals that of charges, the authority sets $Z_{B}=Z_{0}-E[q]$, where $Z_{0}$ is the initial effluent level. Thus it maximises:

$$
E\left[B(q)-\mu . C(q, \theta)-(\mu-1) p\left(Z_{0}-q\right)\right] .
$$

\subsection{Optimal scheme of freely allocated permits}

The solution $\hat{q}_{R N}$ (for revenue-neutral) proceeds from the first-order condition:

$$
B^{\prime}(\hat{q})=\mu . E\left[C_{q}(\hat{q}, \theta)\right]+(\mu-1) E\left[p_{q}(\hat{q}, \theta) Z_{0}-p(\hat{q}, \theta)-p_{q}(\hat{q}, \theta) q\right]
$$

\footnotetext{
${ }^{11}$ Cf. Boemare and Quirion (2002) and Tietenberg (2002) on tradable permits, and Ekins (1999) on taxes.
} 
By the expression of marginal abatement cost (3), marginal environmental benefit (5) and (6):

$\hat{q}_{R N}=\frac{b_{1}-(\mu-1) c_{2} \cdot Z_{0}-c_{1}}{b_{2}+(2-\mu) c_{2}}$

The price of the permits equals marginal abatement cost:

$p\left(\hat{q}_{R N}, \theta\right)=c_{1}+\theta+c_{2} \frac{b_{1}-(\mu-1) c_{2} \cdot Z_{0}-c_{1}}{b_{2}+(2-\mu) c_{2}}$

As in the previous case, we are back to Weitzman's results if $\mu=1$. For all reasonable values of $\mu$, i.e., $\mu \in(1,2)$, the optimal quantity and resulting permits price are lower than in first-best: $\hat{q}_{R N}<\hat{q}_{F B}$ and $p\left(\hat{q}_{R N}, \theta\right)<p\left(\hat{q}_{F B}, \theta\right)$.

\subsection{Optimal ex ante non-revenue-raising charge-subsidy scheme}

The authority chooses the tax rate $\tilde{p}_{R N}$ that maximises the expected surplus given the response function $h(p, \theta)$ :

$$
\tilde{p}=\arg \max _{p} E\left[B(h(\tilde{p}, \theta))-\mu \cdot C(h(\tilde{p}, \theta), \theta)-(\mu-1) \tilde{p}\left(Z_{0}-h(\tilde{p}, \theta)\right)\right]
$$

The first-order condition is:

$$
E\left[B^{\prime}(h(\tilde{p}, \theta)) h_{p}(\tilde{p}, \theta)\right]=\mu \cdot E\left[C_{q}(h(\tilde{p}, \theta), \theta) h_{p}(\tilde{p}, \theta)\right]+(\mu-1)\left(Z_{0}-h(\tilde{p}, \theta)-h_{p}(\tilde{p}, \theta) \tilde{p}\right)
$$

which yields:

$\tilde{p}_{R N}=\frac{b_{2} \cdot c_{1}+c_{2}\left(b_{1}-\left(c_{1}+c_{2} \cdot Z_{0}\right)(\mu-1)\right)}{b_{2}-c_{2}(\mu-2)}$

hence: $h\left(\tilde{p}_{R N}, \theta\right)=Z_{0}-\frac{\theta}{c_{2}}+\frac{b_{1}-c_{1}-\left(b_{2}+c_{2}\right) Z_{0}}{b_{2}-c_{2}\left(\mu-c_{2}\right)}$. 


\subsection{Comparison of non-revenue-raising price and quantity instruments}

Once again, both instruments yield the same optimal expected level of abatement and the same optimal expected permits price/rate of tax and subsidy:

$E\left[h\left(\tilde{p}_{R N}, \theta\right)-\hat{q}_{R N}\right]=0$

$E\left[\tilde{p}_{R N}-p\left(\hat{q}_{R N}, \theta\right)\right]=0$

The difference between both instruments in terms of expected environmental benefit and primary cost, is once again the same:

$$
\begin{aligned}
& E\left[B\left(h\left(\tilde{p}_{R N}, \theta\right)\right)-B\left(\hat{q}_{R N}\right)\right]=-\frac{b_{2} \sigma^{2}}{2 c_{2}{ }^{2}} \leq 0 \\
& E\left[C\left(h\left(\tilde{p}_{R N}, \theta\right), \theta\right)-C\left(\hat{q}_{R N}, \theta\right)\right]=-\frac{\sigma^{2}}{2 c_{2}} \leq 0
\end{aligned}
$$

The social surplus of the ex ante optimal tax, as compared to the ex ante optimal permit scheme, is:

$$
\begin{aligned}
& \Delta_{R N} \equiv E\left[B\left(h\left(\tilde{p}_{R N}, \theta\right)\right)-\mu \cdot C\left(h\left(\tilde{p}_{R N}, \theta\right), \theta\right)-(\mu-1)\left(Z_{0}-h\left(\tilde{p}_{R N}, \theta\right)\right) \tilde{p}_{R N}\right] \\
& -E\left[B\left(\hat{q}_{R N}\right)-\mu \cdot C\left(\hat{q}_{R N}, \theta\right)-(\mu-1)\left(Z_{0}-\hat{q}_{R N}\right) p\left(\hat{q}_{R N}, \theta\right)\right]=\frac{\sigma^{2}\left(\mu \cdot c_{2}-b_{2}\right)}{2 c_{2}{ }^{2}}
\end{aligned}
$$

Comparing ( $\left.8^{\prime}\right)$ with (8), we see that the comparative advantage of the price instrument over the quantity one is the same with revenue-raising or non-revenue-raising-instruments: $\Delta_{R N}=\Delta_{R R}>\Delta_{F B}$. This can be explained by the equality between the expected value of free permits and the baseline effluent right. This is not surprising since the expected price/tax and subsidy rate and the expected abatement level are the same for both instruments. 


\subsection{Contingent non-revenue-raising instrument}

The abatement resulting from the contingent instrument is again computed by maximizing welfare:

$q_{R N}^{*}=\frac{b_{1}-c_{1}-\theta-c_{2} \cdot Z_{0}(\mu-1)}{b_{2}+c_{2}(2-\mu)}$

If $\mu=1$, we are back again to Ireland's result. Otherwise, the optimal abatement may be lower or higher. The advantage of the contingent instrument over the quantity one is:

$$
\begin{aligned}
& \Delta\left(C I_{R N}, Q_{R N}\right) \equiv E\left[B\left(q_{R N}^{*}\right)-\mu \cdot C\left(q_{R N}^{*}, \theta\right)-(\mu-1)\left(Z_{0}-q_{R N}^{*}\right) p\left(q_{R N}^{*}, \theta\right)\right] \\
& -E\left[B\left(\hat{q}_{R N}\right)-\mu \cdot C\left(\hat{q}_{R N}, \theta\right)-(\mu-1)\left(Z_{0}-\hat{q}_{R N}\right) p\left(\hat{q}_{R N}, \theta\right)\right]=\frac{\sigma^{2}}{2\left(b_{2}+c_{2}(2-\mu)\right)}
\end{aligned}
$$

This expression is positive and increased by pre-existing distortions. The advantage of the contingent price instrument over the standard price instrument is:

$$
\begin{aligned}
& \Delta\left(C I_{R N}, P_{R N}\right) \equiv E\left[B\left(q_{R N}^{*}\right)-\mu \cdot C\left(q_{R N}^{*}, \theta\right)-(\mu-1)\left(Z_{0}-q_{R N}^{*}\right) p\left(q_{R N}^{*}, \theta\right)\right] \\
& -E\left[B\left(h\left(\tilde{p}_{R N}, \theta\right)\right)-\mu \cdot C\left(h\left(\tilde{p}_{R N}, \theta\right), \theta\right)-(\mu-1)\left(Z_{0}-h\left(\tilde{p}_{R N}, \theta\right)\right) \tilde{p}_{R N}\right]=\frac{\left(b_{2}-c_{2}(\mu-1)\right)^{2} \sigma^{2}}{2 c_{2}{ }^{2}\left(b_{2}+c_{2}(2-\mu)\right)}
\end{aligned}
$$

which is also positive and may be increased or decreased by pre-existing distortions, depending on the parameters.

\section{Optimal acceptable instruments}

There is no a priori rationale for allocating all permits in a free manner, nor for setting the baseline effluent right of a charge-subsidy scheme such that it does not provide any public revenue. For instance, as Bovenberg and Goulder (2000), Burtraw et al. (2001) or Jensen and Rasmussen (2000) have shown, for greenhouse gases abatement, freely allocated upstream permits are likely to overcompensate the fossil fuel industry. In these simulations, profits in 
regulated sectors rise following the limitation of pollution, because firms pass a significant part of the permits' cost on to consumers, while they receive permits for free. In such a situation, it makes sense for the authority to grandfather only a part of the permits and auction the rest, thus providing some public revenues without cutting the profits of the regulated industry.

Thus, in this section, we consider that the regulated industry kills any proposal that poses it an expected burden ${ }^{12}$ higher than an exogenous level $M$. The rationale for such an assumption is that for regulated industry, political mobilisation is costly, and worthless if the expected burden of the regulation is small. The authority now faces an acceptability constraint:

$$
E[C(q, \theta)]+E\left[p\left(Z_{0}-q-Z_{B}\right)\right] \leq M .
$$

This is equivalent to $E\left[p \cdot Z_{B}\right] \geq E\left[C(q, \theta)+p\left(Z_{0}-q\right)-M\right]$. Two cases may thus occur:

If the acceptability constraint is not binding, e.g. because abatement is cheap or because $M$ is high, the authority sets $Z_{B}=0$ and maximises $E[B(q)-\mu . C(q, \theta)]$. If not we are back to the situation dealt with in section 3 .

On the opposite, if the acceptability constraint is binding, the authority chooses the minimum amount for $Z_{B}$ that satisfies the constraint. It thus maximises $E\left[B(q)-\mu \cdot C(q, \theta)-(\mu-1)\left(C(q, \theta)+p\left(Z_{0}-q\right)-M\right)\right]$. In the rest of this fifth section we derive results for this second case, i.e., assuming that the acceptability constraint is binding.

\subsection{Optimal permit scheme with a mix of free allocation and auctioning}

The solution $\hat{q}_{P R R}$ (for partly revenue-raising) proceeds from the first-order condition:

$$
B^{\prime}(\hat{q})=(2 \mu-1) E\left[C_{q}(\hat{q}, \theta)\right]+(\mu-1) E\left[p_{\hat{q}}(\hat{q}, \theta) Z_{0}-p(\hat{q}, \theta)-p_{\hat{q}}(\hat{q}, \theta) q\right]
$$

\footnotetext{
${ }^{12}$ One could argue that firms are interested in the actual, not expected, burden they will face. However, as stressed, e.g., by Kehoane et al. (1998) or Lévêque ed. (1996), most firms are involved in lobbying through organised interest groups. Would a single firm disclose its private abatement costs to such a lobbying group, it would give away some strategic information to its competitors.
} 
By the expression of marginal abatement cost (3), marginal environmental benefit (5) and (6):

$\hat{q}_{P R R}=\frac{b_{1}-\mu \cdot c_{1}-(\mu-1) c_{2} \cdot Z_{0}}{b_{2}+c_{2}}$

The price of the permits equals marginal abatement cost:

$p\left(\hat{q}_{P R R}, \theta\right)=c_{1}+c_{2} \frac{b_{1}-\mu \cdot c_{1}-(\mu-1) c_{2} \cdot Z_{0}}{b_{2}+c_{2}}+\theta$.

As in the two previous cases, we are back to Weitzman's results if $\mu=1$. For $\mu>1$, $\hat{q}_{P R R}<\hat{q}_{R R}<\hat{q}_{F B}$ and $p\left(\hat{q}_{P R R}, \theta\right)<p\left(\hat{q}_{R R}, \theta\right)<p\left(\hat{q}_{F B}, \theta\right)$. When the mix of free and auctioned permits is chosen by the regulator in order to overcome industry opposition, every increase in pollution abatement implies a bigger transfer in the form of free permits. Hence, the authority sets a lower target, compared to the situation without transfer. However, no general comparison can be made between $\hat{q}_{P R R}$ and $\hat{q}_{R N}$, nor between $\hat{q}_{R N}$ and $\hat{q}_{R R}$. Indeed, when all the permits are freely allocated, an increase in pollution abatement decreases the number of permits transferred, which provides an incentive for the authority to set a tougher target. On the other hand, however, this increase in abatement raises the permits price and thus the cost of the transfer, hence the overall result depends on the parameters.

\subsection{Optimal charge-subsidy scheme with a baseline effluent right below expected emissions}

The authority chooses the tax rate $\tilde{p}_{P R R}$ that maximises the expected surplus given the response function $h(p, \theta)$ :

$\tilde{p}=\arg \max _{p} E\left[B(h(\tilde{p}, \theta))-\mu \cdot C(h(\tilde{p}, \theta), \theta)-(\mu-1)\left(C(h(\tilde{p}, \theta), \theta)+\tilde{p}\left(Z_{0}-h(\tilde{p}, \theta)-M\right)\right)\right]$

The first-order condition is:

$E\left[B^{\prime}(h(\tilde{p}, \theta)) h_{p}(\tilde{p}, \theta)\right]=(2 \mu-1) E\left[C_{q}(h(\tilde{p}, \theta), \theta) h_{p}(\tilde{p}, \theta)\right]+(\mu-1)\left(Z_{0}-h(\tilde{p}, \theta)-h_{p}(\tilde{p}, \theta) \tilde{p}\right)$ 
which yields:

$\tilde{p}_{P R R}=\frac{b_{2} \cdot c_{1}+c_{2}\left(b_{1}-\left(c_{1}+c_{2} \cdot Z_{0}\right)(\mu-1)\right)}{b_{2}+c_{2}}$

hence: $h\left(\tilde{p}_{P R R}, \theta\right)=\frac{b_{1} \cdot c_{2}-b_{2} \cdot \theta-c_{2}\left(\theta+c_{2} \cdot Z_{0}(\mu-1)+c_{1} \cdot \mu\right)}{c_{2}\left(b_{2}+c_{2}\right)}$.

\subsection{Comparison of "partly revenue raising" price and quantity instruments}

Once again, both instruments yield the same optimal expected level of abatement and the same optimal expected price/tax:

$$
\begin{aligned}
& E\left[h\left(\tilde{p}_{P R R}, \theta\right)-\hat{q}_{P R R}\right]=0 \\
& E\left[\tilde{p}_{P R R}-p\left(\hat{q}_{P R R}, \theta\right)\right]=0
\end{aligned}
$$

The difference between both instruments, in terms of expected environmental benefit and primary cost, is once again the same:

$$
\begin{aligned}
& E\left[B\left(h\left(\tilde{p}_{P R R}, \theta\right)\right)-B\left(\hat{q}_{P R R}\right)\right]=-\frac{b_{2} \sigma^{2}}{2 c_{2}{ }^{2}} \leq 0 \\
& E\left[C\left(h\left(\tilde{p}_{P R R}, \theta\right), \theta\right)-C\left(\hat{q}_{P R R}, \theta\right)\right]=-\frac{\sigma^{2}}{2 c_{2}} \leq 0
\end{aligned}
$$

The difference between both instruments, in terms of expected transfer, is:

$$
E\left[C\left(h\left(\tilde{p}_{P R R}, \theta\right), \theta\right)+\left(Z_{0}-h\left(\tilde{p}_{P R R}, \theta\right)\right) \tilde{p}_{P R R}-M-C\left(\hat{q}_{P R R}, \theta\right)-\left(Z_{0}-\hat{q}_{P R R}\right) p\left(\hat{q}_{P R R}, \theta\right)+M\right]=-\frac{\sigma^{2}}{2 c_{2}} \leq 0
$$

The expected burden of the regulation (excluding the transfer) is higher for permits than for taxes (cf. (10) and the explanation above, paragraph 3.4). As a consequence, the authority has to transfer a higher financial amount under the form of free permits rather than as baseline effluent right of the charge-subsidy scheme. 
The social surplus of the ex ante optimal tax, as compared to the ex ante optimal permit scheme, is:

$$
\begin{aligned}
& \Delta_{P R R} \equiv E\left[\begin{array}{l}
{\left[B\left(h\left(\tilde{p}_{P R R}, \theta\right)\right)-\mu \cdot C\left(h\left(\tilde{p}_{P R R}, \theta\right), \theta\right)\right.} \\
\left.-(\mu-1)\left(C\left(h\left(\tilde{p}_{P R R}, \theta\right), \theta\right)+\left(Z_{0}-h\left(\tilde{p}_{P R R}, \theta\right)-M\right) \tilde{p}_{P R R}\right)\right]
\end{array}\right] \\
& -E\left[B\left(\hat{q}_{P R R}\right)-\mu \cdot C\left(\hat{q}_{P R R}, \theta\right)-(\mu-1)\left(C\left(\hat{q}_{P R R}, \theta\right)+\left(Z_{0}-\hat{q}_{P R R}-M\right) p\left(\hat{q}_{P R R}, \theta\right)\right)\right] \\
& =\frac{\sigma^{2}\left((2 \mu-1) c_{2}-b_{2}\right)}{2 c_{2}{ }^{2}}
\end{aligned}
$$

Comparing ( $\left(8^{\prime \prime}\right)$ with $\left(8^{\prime}\right)$ and (8), we notice that the comparative advantage of price instruments over quantity ones is greater than with an exogenous (positive as in section 4, or nil as in section 3) quantity of free permits or baseline effluent right: $\Delta_{P R R}>\Delta_{R R}=\Delta_{R N}>\Delta_{F B}$.

Quantitatively, this result should not be considered trivial. Goulder et al. (1999b)'s estimate of the $\mu$ parameter is 1.27 . This means that even if the marginal benefit function is $50 \%$ more steeply sloped than the marginal cost function (normally arguing for a quantity instrument), the price instrument should be preferred.

\subsection{Contingent "partly revenue raising" instrument}

The abatement resulting from the contingent instrument is again computed by maximizing welfare:

$$
q_{P R R}^{*}=\frac{b_{1}+c_{2} \cdot Z_{0}-\left(c_{1}+c_{2} \cdot Z_{0}+\theta\right) \mu}{b_{2}+c_{2}}
$$

If $\mu=1$, we are back again to Ireland's result. Otherwise, the optimal abatement is lower. The advantage of the contingent instrument over the quantity one is:

$$
\begin{aligned}
& \Delta\left(C I_{P R R}, Q_{P R R}\right) \equiv E\left[B\left(q_{P R R}^{*}\right)-\mu \cdot C\left(q_{P R R}^{*}, \theta\right)-(\mu-1)\left(C\left(q_{P R R}^{*}, \theta\right)+\left(Z_{0}-q_{P R R}^{*}-M\right) p\left(q_{P R R}^{*}, \theta\right)\right)\right] \\
& -E\left[B\left(\hat{q}_{P R R}\right)-\mu \cdot C\left(\hat{q}_{P R R}, \theta\right)-(\mu-1)\left(C\left(\hat{q}_{P R R}, \theta\right)+\left(Z_{0}-\hat{q}_{P R R}-M\right) p\left(\hat{q}_{P R R}, \theta\right)\right)\right]=\frac{\mu^{2} \sigma^{2}}{2\left(b_{2}+c_{2}\right)}
\end{aligned}
$$


This expression is positive and increased by pre-existing distortions. The advantage of the contingent price instrument over the standard price instrument is:

$$
\begin{aligned}
& \Delta\left(C I_{P R R}, P_{P R R}\right) \equiv E\left[B\left(q_{P R R}^{*}\right)-\mu \cdot C\left(q_{P R R}^{*}, \theta\right)-(\mu-1)\left(Z_{0}-q_{P R R}^{*}\right) p\left(q_{P R R}^{*}, \theta\right)\right] \\
& -E\left[\begin{array}{l}
B\left(h\left(\tilde{p}_{P R R}, \theta\right)\right)-\mu \cdot C\left(h\left(\tilde{p}_{P R R}, \theta\right), \theta\right) \\
-(\mu-1)\left(C\left(h\left(\tilde{p}_{P R R}, \theta\right), \theta\right)+\left(Z_{0}-h\left(\tilde{p}_{P R R}, \theta\right)-M\right) \tilde{p}_{P R R}\right)
\end{array}\right]=\frac{\left(b_{2}-c_{2}(\mu-1)\right)^{2} \sigma^{2}}{2 c_{2}{ }^{2}\left(b_{2}+c_{2}\right)}
\end{aligned}
$$

which is also positive and may be increased or decreased by pre-existing distortions, depending on the parameters.

\section{Reducing $\mathrm{CO}_{2}$ emissions from energy-intensive industry: an appropriate context for applying a charge-subsidy scheme}

From the late eighties to the late nineties, there was a broad consensus, among economists and policy-makers willing to reduce greenhouse gas emissions, in favour of a carbon tax. Since then, tradable permits have received a growing attention, and a number of OECD countries as well as the European Union (Boemare and Quirion, 2002) are planning or developing such systems. Among the factors that can explain this switch is the opposition of industry lobby groups to taxes, which led to the rejection of the energy and carbon tax proposals in the European Union and the U.S. in the early and mid nineties, and the relative preference of these lobby groups for (freely allocated) permits (NHO, 2001) ${ }^{13}$. However, in the light of our analysis, this preference largely stems from the oversight of a charge-subsidy scheme, which combines two advantages, from the industry point of view: like grandfathered permits, it may only charge marginal emissions, and like a tax, it provides some flexibility concerning the overall abatement.

\footnotetext{
13 Among other factors are, first, the success of the U.S. $\mathrm{SO}_{2}$ tradable permits scheme and, second, the Kyoto Protocol to the UN Convention on climate change, which sets tradable permits among developed countries. However, none of them is a rigorous rationale for preferring a quantity to a price instrument in this field. First, some countries, in particular Sweden, have succeeded in cutting $\mathrm{SO}_{2}$ emissions through a tax system (Hammar and Löfgren, 2000). Second, the Protocol does not require signatory parties to subject their firms to tradable permits. Nothing prevents them from fulfilling their obligations through a tax or a combination of various policies and measures.
} 
Furthermore, throughout the paper we have assumed that firms are risk-neutral. However, there are several reasons for why firms may act as if they were risk-averse ${ }^{14}$. In such a case, the comparative advantage of taxes over permits would be still higher for regulated firms, since taxes entail less uncertainty on abatement costs than permits.

Admittedly, environmental lobbying groups, in particular administrations in charge of the environment, environmental NGOs and green political parties, obviously prefer an instrument that provides certainty on the environmental objective. This is true if these groups are riskneutral, as soon as the environmental benefit curve is concave. Furthermore, the above argument on risk-aversion is particularly important for groups that generally advocate the precautionary principle.

Nevertheless, do tradable permits provide environmental certainty in the particular field of climate change? Of course, one can design such a system ${ }^{15}$, but the bulk of current proposals, including the European Commission directive proposal (2001) do not provide much more environmental certainty than taxes. First, they aim at regulating emissions downstream, at the fossil fuel consumer level, not upstream, at the level of fossil fuel producers and importers. As a consequence, they fail to regulate diffuse sources, in particular transportation and buildings, which are the more rapidly growing sector, and the ones for which uncertainty concerning future emissions is the highest. Second, these proposals often advocate exchangeability between the domestic permits they would create and the international permits of the Kyoto Protocol ${ }^{16}$. The Bonn and Marrakech agreements which finalise the Protocol incorporate most of the "loopholes" environmental NGOs have been fighting against for years: credits for business-as-

\footnotetext{
${ }^{14}$ Some of the factors that can be invoked are non-diversified owners, liquidity constraints, costly financial distress, and non-linear tax systems. And even if owners themselves wish to maximise expected profits, delegation of control to a risk-averse manager, whose payment is linked to firm performance, may cause the firm to behave in a risk-averse manner. Empirically, the reluctance to bear risk is evidenced by the extent of corporate hedging activity (Asplund, 1999).

${ }^{15}$ See in particular Kopp et al. (1999)'s proposal for the U.S.
} 
usual activities, for nuclear projects, for environmentally damaging tree plantations (Greenpeace, 2000)... Both points are heavily criticised by environmental NGOs ${ }^{17}$, who would predominantly prefer a price instrument, provided that it is comprehensive and not opened to dubious international credits.

Last, on a more ideological level, most environmental NGOs and green parties traditionally prefer taxes to tradable permits, often denounced as "rights to pollute". The U.S. NGO Environmental Defense is an exception in this respect.

Thus, political acceptability considerations add up with economic efficiency considerations ${ }^{18}$ to favour a price rather than a quantity instrument against $\mathrm{CO}_{2}$ emissions.

\section{Conclusion}

Introducing pre-existing distortionary taxes in Weitzman's (1974) stochastic framework provides new insights on the comparative advantage of taxes over permits. First, this comparative advantage is greater in second- than in first-best conditions. This conclusion holds for revenue-raising instruments, i.e., auctioned permits vs. a tax on every unit of pollution, as well as for non-revenue-raising instruments, i.e., freely allocated permits vs. a charge-subsidy scheme such that the expected amount of subsidies equals that of charges.

There is no a priori rationale for allocating all permits in a free manner, nor for setting the baseline effluent right of a charge-subsidy scheme such that it does not provide any public revenue. It is more consistent to assume that the regulated industry kills any proposal that poses

\footnotetext{
16 The European Commission directive proposal (2001) does not decide on this point which will be addressed by another directive proposal, currently prepared by the Commission.

${ }^{17}$ See the reaction from Climate Action Network Europe (2001) to the European Commission proposal. CAN-E is the coordinating office for environmental groups in Western Europe working on climate change issues.

${ }^{18}$ Most economists, e.g. Hourcade (1994) or Pizer (1999), argue that taxes would perform better than quotas to fight against global warming, because greenhouse gases are a stock pollutant, so the short-term damage curve is flat.
} 
it too high an expected burden, and that the authority takes this constraint into account to set the transferred amount. In such a setting, and this is our second important result, permits require a greater transfer. As a consequence, the comparative advantage of taxes over permits is still reinforced when the amount transferred to regulated firms is chosen by the regulator so as to overcome industry pressure.

We also compare the expected net benefit of these two instruments to a "contingent" instrument which leads to the ex post optimum. Such instruments have potential drawbacks and involve additional complexity. This explains why "single-value instruments", i.e., linear taxes and tradable permit schemes, are more and more common in environmental policy and why they are still worth studying. However, knowing the expected advantage of a hypothetical contingent instrument over the single-value ones is interesting to decide whether the theoretical advantage of the contingent instrument is worth the additional complexity. It turns out that the superiority of the contingent instrument over the quantity instrument is higher than in first-best. No general result may be derived concerning the influence of pre-existing distortions on the superiority of the contingent instrument over the price instrument.

This article aims at providing analytical rather than quantitative results. However, a preliminary analysis shows that our findings should not be considered quantitatively trivial. Taking an estimate of the marginal cost of public funds from the literature, even if the marginal benefit function is $50 \%$ more steeply sloped than the marginal cost function (normally arguing for a quantity instrument), the price instrument should be preferred if the amount transferred is firms is set so as to overcome industry pressure.

Last, we provide several arguments indicating that in the case of climate change, a chargesubsidy scheme could be better accepted than a tradable permit system, both by industry and environmental groups. 
Hence, in the future, we would like to integrate this paper's considerations in a numerical general equilibrium model applied to climate change. This integration would also let us know whether our results would remain in a more complex model, in particular one exhibiting a "strong double dividend" along one of the lines presented in the second paragraph. 


\section{Appendix}

Schöb (1996) wrote the first paper on the comparison of price and quantity instruments in a second-best world with distortionary taxation. He concludes that the first-best choice rule demonstrated by Weitzman (1974) remains valid in second-best. However, his paper is based on a partial equilibrium model inspired by Lee and Misiolek (1986) which, as we argue here, is not consistent with the more recent general equilibrium literature on the double-dividend summarised e.g. by Goulder (1994) or Bovenberg and Goulder (2001). In the language introduced by Parry (1995), Schöb's model reflects the revenue-recycling effect but not the taxinteraction effect. Too see why, let us restate the welfare function Schöb (1996, p. 403, equation 1) assumes that the government maximises:

$W=B(x)-q \cdot x-e(x)+\delta . t \cdot x$

Where $x$ is the consumption of a polluting good, $B$ the gross private benefit from this consumption, $q$ the marginal private production cost, assumed constant, $e$ the environmental damage, $\delta$ the marginal excess burden, and $t$ the environmental tax rate, t.x being the environmental tax revenue. Rewriting (A.1) with our notations, we got:

$W=B(q)-C(q)+(\mu-1) p\left(Z_{0}-q-Z_{B}\right)$

There are two differences with our own objective function: $\mu$ does not appear before $C$ and the revenue from a tax or auctioned permits now appears positively in the welfare function. To see which formulation is the most appropriate, let us focus on the influence of a shift from first-best to second-best, or more generally of an increase in the marginal cost of public funds (MCPF).

From equation (A.2), Schöb (1996, p. 404, equation. 4) derives the optimal tax rate $t^{*}$ :

$$
t^{*}=\frac{M E D}{1+\delta\left(1-\frac{1}{\tau}\right)}
$$


Where $\tau$ is the tax elasticity ${ }^{19}$. We see that in Schöb's formulation, following a rise in the marginal cost of public funds, a higher environmental tax should be set if and only if we are on the Laffer-efficient side of the tax revenue curve, i.e. if the tax elasticity is smaller than one. This is consistent with the earlier partial equilibrium models which founded the strong version of the double dividend hypothesis but clearly contradicts the conclusions of the more recent general equilibrium work summarised e.g. by Goulder (1994). According to this literature, as soon as the MCPF exceeds unity, a lower tax rate than in first-best should be set. More precisely, quoting Goulder (1994, p. 27),

"From Bovenberg and van der Ploeg's analysis, in a second-best setting the optimal environmental tax rate, $t^{*}$, is given by:

$$
t^{*}=\frac{M E D}{\mu}
$$

where $\mu$ is the marginal cost of public funds."

Bovenberg and Goulder (2001, p. 8) also conclude that

"the higher the MCPF, the smaller the optimal environmental tax, ceteris paribus."

In their model, moving from first- to second-best, the optimal tax rate is divided by the MCPF: compare equations (16) and (23) in their paper.

As pointed out by Goulder (1994, footnote 56), results by Lee and Misiolek are consistent with the Bovenberg and van der Ploeg formula only if the fact that pre-existing taxes increase the marginal abatement cost is taken into account. This is not the case in the paper by Schöb (1986), as is clear from equation (A.1) above. On the opposite, our optimal tax formula from 3.2 is

\footnotetext{
${ }^{19}$ The tax elasticity indicates the percentage at which the demand for the polluting good will be reduced if the tax rate is increased by $1 \%$.
} 
compatible with Bovenberg and van der Ploeg's formulae: taking a constant $M E D$, i.e., $b_{2}=0$ in our model, the optimal tax is $\tilde{p}_{R R}=\frac{b_{1}}{\mu}=\frac{M E D}{\mu}$. 


\section{References}

Asplund, M. (1999) "Risk-Averse Firms in Oligopoly", Gothenburg University working paper

Baumol, W. and W. Oates (1988) The theory of environmental policy, $2^{\text {nd }}$ edition, Cambridge University Press, Cambridge

Boemare, C. and P. Quirion (2002) "Implementing Greenhouse Gas Trading in Europe: Lessons from Economic Literature and International Experiences", Ecological Economics, 43: 213-230

Bovenberg, L. and L. Goulder (2000) Neutralising the adverse industry impacts of $\mathrm{CO}_{2}$ abatement policies: What does it cost?, Fondazione Eni Enrico Mattei Working Paper 68.2000

Bovenberg, L. and L. Goulder (2001) Environmental taxation and regulation, NBER working paper 8458, NBER, Cambridge, Ma.

Burtraw, D., K. Palmer, R. Bharvirkar and A. Paul (2001) The effect of allowance allocation on the cost of carbon emission trading, Resources for the Future Discussion Paper 01-30

Climate Action Network Europe (2001) Emission trading in the EU, December, Brussels

Collinge, R. and W. Oates (1980) Efficiency in pollution control in the short and the long run: A system of rental emissions permits", Canadian Journal of Economics, 15, 346-54

Ekins, P. (1999) "European environmental taxes and charges: recent experience, issues and trends", Ecological Economics, 31, 39-62

Ekins, P. and S. Speck (1999) "Competitiveness and exemptions from environmental taxes in Europe", Environmental and Resource Economics, 13: 369-96

European Commission (2001) Proposal for a directive establishing a framework for greenhouse gas emissions trading within the European Community - October 23, Brussels

Fullerton, D. and G. Metcalf (2001) "Environmental controls, scarcity rents, and pre-existing distortions", Journal of Public Economics, 80: 249-67 
Goulder, L. (1995) "Environmental Taxation and the Double Dividend: A Reader's Guide", International Tax and Public Finance, 2(2): 157-183

Goulder, L, I. Parry and D. Burtraw (1999a) "revenue-raising vs. other approaches to environmental protection: the critical significance of pre-existing tax distortions", RAND Journal of Economics, 28(4): 708-31

Goulder, L, I. Parry, R. Williams and D. Burtraw (1999b) "The cost-effectiveness of alternative instruments for environmental protection in a second-best setting", Journal of Public Economics, (72)3: 329-360

Greenpeace (2000) Cheating the Kyoto protocol: Loopholes undermine environmental effectiveness, November, Amsterdam

Hammar, H. and A. Löfgren (2000) The determinants of sulphur emissions from oil consumption in Swedish manufacturing industry, 1976-1995, Working paper, May, Gothenburg University, Sweden

Helioui, K. (1997) Double dividende d'une écotaxe en présence de fluctuations conjoncturelles et de rigidités de l'emploi, CIRED working paper, Nogent-sur-Marne, France

Hourcade, J.-C. (1994) "Economic issues and negotiation on global environment", in C. Carraro (ed.) Trade, innovation, environment, Kluwer

Intergovernmental Panel on Climate Change (2001) Climate Change 2001: Mitigation - Third assessment report of Working group III, chap. 8: "Global, regional, and national costs and cobenefits of mitigation", Cambridge University Press

Ireland, N. (1977) "Ideal prices vs. prices vs. quantities", Review of Economic Studies, 44(1): $183-186$ 
Jensen, J. and T. Rasmussen (2000) "Allocation of $\mathrm{CO}_{2}$ emissions permits: A general equilibrium analysis of policy instruments", Journal of Environmental Economics and Management, 40: 11-36

Kehoane, N., R. Revesz and R. Stavins (1998) "The positive political economy of instrument choice in environmental policy", in P. Portney and R. Schwab, eds., Environmental economics and public policy, Edward Elgar, London

Kopp, R. et al. (1999) Domestic early action: a mandatory, comprehensive permit trading system, mimeo, Resources for the Future, Washington DC

Lévêque, F. (ed.) (1996) Environmental policy in Europe - Industry, competition and the policy process, Edward Elgar, London

Mumy, G. (1980) "Long-run efficiency and property rights sharing for pollution control", Public Choice, 35: 59-74

NHO (Confederation of Norwegian business and industry) (2001) Meeting the Kyoto Protocol Commitments - Summary - Domestic emissions trading schemes, January, Oslo, Norway

Parry, I. (1995) "Pollution taxes and revenue recycling", Journal of Environmental Economics and Management, 29: S64-S77

Parry, I. (1997) "Environmental taxes and quotas in the presence of distorting taxes in factor markets", Resource and Energy Economics, 19: 203-220

Parry, I., R. Williams and L. Goulder (1999) "When can carbon abatement policies increase welfare? The fundamental role of distorted factor markets", Journal of Environmental Economics and Management, 37: 52-84

Pezzey, J. (1992) "The symmetry between controlling pollution by price and controlling it by quantity", Canadian Journal of Economics, 25(4): 983-91 
Pizer, W. (1999) "The optimal choice of climate change policy in the presence of uncertainty", Resource and Energy Economics, 21(3-4)

Roberts, M. and M. Spence (1976) "Uncertainty and the choice of pollution control instruments", Journal of Public Economics, 5, April/May

Sandmo, A. (1975) "Optimal taxation in the presence of externalities", Swedish Journal of Economics, 77: 86-98

Schöb, R. (1996) "Choosing the right instrument - the role of public revenues for environmental policy", Environmental and Resource Economics, 8: 399-416

Stavins, R. (1996) "Correlated uncertainty and policy instrument choice", Journal of Environmental Economics and Management, 30: 218-32

Tietenberg, T. (2002) "The Tradable Permits Approach to Protecting The Commons: What Have We Learned?", Fondazione Eni Enrico Mattei Working Paper 36.2002

Unold, W. and T. Requate (2001) Pollution control by options trading under imperfect information, EAERE Conference, 28-30 June, Southampton, U.K.

Weitzman, M. (1974) "Prices vs. Quantities", Review of Economic Studies, 41(4): 447-91 